\title{
MORAL TESTIMONY: TRANSMISSION VERSUS PROPAGATION
}

\author{
Alison Hills \\ St John's College, Oxford
}

\section{$\underline{\text { Abstract }}$}

The status of moral testimony has recently been challenged, for both epistemic and nonepistemic reasons. This paper distinguishes two methods of teaching: transmission, "classic" learning from testimony, that results in second hand knowledge, and propagation which results in first hand knowledge and understanding. Moral propagation avoids most of the epistemic and non-epistemic problems of transmission. Moreover, moral propagation can develop and refine non-cognitive attitudes too. Therefore moral testimony should (and normally does) take the form of moral propagation, not transmission.

\section{Moral testimony.}

If you are not sure what to do, or you are struggling with some difficult moral conundrum, can you learn what is morally right from other people? In particular, can you learn from them by means of moral testimony, that is, testimony that is explicitly of moral propositions, such as "stealing is wrong" or "you should help your friend"?

It might seem obvious that you can. ${ }^{1}$ Surely you are not required to try to think through every single moral problem by yourself? It's commonplace when faced with a tricky moral situation to seek help. You might ask your friends or your parents, a religious leader, or just someone whose judgement you trust. In virtually every domain, there is a division of epistemic labour: some of us become experts and share our knowledge with others. Why shouldn't ethics be exactly the same? Some people have some morally relevant experience than others, or have thought about the matter longer or more carefully; why can't we learn about morality from them, just as we can learn about anything else on which they are an expert?

On the other hand, it is widely thought problematic, or at any rate not ideal, for mature adults to form moral judgements on the basis of moral testimony. ${ }^{2}$ Why? Some reasons are epistemic. You should trust testimony only if the speaker knows what she is talking about. But finding moral experts

\footnotetext{
1 Jones (1999), Sliwa (2012, 2017), Enoch (2014), Lillehammer (2014).

${ }^{2}$ Nickel (2001), McGrath (2009, 2011), Hills (2009, 2010, 2013), Howell (2014), Crisp (2014).
} 
is not easy and it is not obvious whom you should trust. ${ }^{3}$ So perhaps moral judgements based on testimony cannot amount to moral knowledge and should be avoided for that reason.

Other objections are of a different kind. Perhaps in the right circumstances, moral testimony can afford knowledge, but judgements made on that basis have another kind of flaw, moral or practical. If you simply do what you are told, it has been argued, you will lack moral understanding, moral worth, and moral virtue. ${ }^{4}$ Moral knowledge can be taught, through moral testimony, but virtue cannot. What virtue requires is for the learner to acquire good judgement for herself, not merely doing what she is told. ${ }^{5}$ It is not clear that this leaves any room for moral testimony.

So moral testimony seems to be common and necessary but also deeply problematic in various ways. To understand what is going on, we need to distinguish a broader and a narrower sense in which we can learn from testimony. The narrower and more restricted sense is transmission (classic learning by testimony): the speaker asserts that $\mathrm{p}$ and the hearer takes her word: her reason for belief is the speaker's assertion. The broader and more capacious sense is propagation, whereby what the speaker says is an epistemic influence on the hearer, but not her reason for belief. Transmission and propagation differ in very many ways: from the speaker's speech act (transmission requires assertion (or similar), propagation does not) to the uptake from the hearer (in transmission, the hearer takes the assertion as a reason for belief; in propagation she takes what is said as a reason for inquiry); and in the resulting epistemic state (successful transmission results in second hand knowledge but not understanding, successful propagation results in first hand knowledge and understanding).

Once we recognize the distinction between transmission and propagation, we can draw a number of important conclusions. First, that the problems that plague moral testimony are mitigated by propagation (though not all disappear entirely). Propagation, unlike transmission, can pass on moral understanding and can help you to respond to moral reasons in the way required for moral virtue and morally worthy action. Moreover, whereas moral transmission typically does not affect our emotions or moral motivation, moral propagation often influences our non-cognitive attitudes too. ${ }^{6}$ In particular it can extend our sympathy, by prompting imaginative engagement with different points of view, and draw on emotional responses (including anger, blame and similar), directing them in new ways, to inform and be informed by our moral understanding. Finally, taking moral advice and discussing moral problems with others is usually a matter of learning from others by propagation, rather than transmission.

\footnotetext{
${ }^{3}$ Goldman (2001); Driver (2006), Cholbi (2007) McGrath (2007, 2011).

${ }^{4}$ Hills $(2009,2010)$, Howell (2014).

${ }^{5}$ Annas (2011), p. 17.

${ }^{6}$ A point emphasized by Fletcher (2016) and Howell (2014).
} 
I conclude that those who thought that learning from moral testimony was rare and problematic were right, with regard to moral transmission (classic learning from testimony). But nevertheless we can and often do learn from others about morality by means of moral propagation.

\section{Propagation and transmission}

Normally it is not difficult for an expert to pass on propositional knowledge by testimony. Standardly, we learn from testimony in something like the following way, which I shall call transmission. ${ }^{7}$ You know I am a reliable, trustworthy person, and you ask me if there's anyone on the street. I tell you:

"There are three children playing on the street"

You understand what I say and you trust me. Trusting here means that you take my word: you form the belief that there are three children playing on the street and the reason for that belief is my testimony, expressing my knowledge. Your new knowledge thus epistemically depends on mine. Because of this special dependence, it is sometimes said that testimonial knowledge is second hand. ${ }^{8}$ We can define transmission by testimony as follows:

Transmission of knowledge by testimony: the speaker's knowledge that $\mathrm{p}$, expressed through her testimony, is an epistemic ground of the learner's knowledge that $\mathrm{p}$.

Contrast this with another way that testimony can pass on knowledge, which I call propagation. Suppose again you ask me if there's anyone on the street and I tell you:

"There's a man outside on the street dressed as a tree!"

You find this hard to believe, so you don't take my word for it. I knew you would not: after all, it's very unusual for a man to dress as a tree. However, you are intrigued. So you go outside - as I intended - and sure enough you see that I am right. Now you know that there is a man dressed as a tree on the street too: I have successfully passed on my knowledge. But this is not a classic case of learning from testimony: the result isn't even testimonial knowledge. You did not trust me in the way that is essential to transmission: you did not take my word; you did not take what I said as a reason for belief.

\footnotetext{
${ }^{7}$ This is a standard account of learning from testimony, as e.g. in Adler (2012), Fricker (2006), Faulkner (2011), p 3. The term "transmission" is used in a narrower sense as a specific account of how knowledge is passed on through testimony (as in e.g. in Burge (1993) but I will be using it here more broadly.

${ }^{8}$ Fricker (2006).
} 
It is sometimes said that the testimony here does not have an epistemic role. It is a mere cause of your belief, as a blow to the head might cause you to believe that $\mathrm{p}$. But that is not right. There can be epistemic functions other than providing epistemic reasons. The testimony gave you a special sort of practical reason, but with a distinctively epistemic flavour: a reason to conduct an investigation into the truth of a particular hypothesis, namely, whether there really is a man on the street dressed as a tree. The testimony gave you a motivation to investigate and set the terms of the investigation: a plainly epistemic role, but not one that necessarily raised your credence in the hypothesis prior to the investigation (or necessarily gave you a reason to have a higher credence, rather than a reason to find other reasons for belief).

So propagation works by encouraging the hearer to find other, non-testimonial reasons for belief. Here the investigation was a matter of observation; other inquiries might involve reasoning too and perhaps other methods. So the knowledge you eventually gain from propagation is not second hand, because it is not epistemically dependent on someone else's knowledge (that has been transmitted to you, and is the basis of your belief). In this example, the resulting knowledge is perceptual. In other cases it may be based on reasoning, drawing inferences from what you know or what you can find out. But knowledge from propagation is always first hand.

We can therefore define propagation as follows:

Propagation of knowledge: the speaker's knowledge that $\mathrm{p}$, expressed through her testimony, is a causal factor and an epistemic influence on the learner's gaining knowledge that $\mathrm{p}$, but not an epistemic ground of it.

In principle there is a clear distinction between these two uses of testimony, transmission and propagation, and between first and second hand knowledge. In practice, things are more complicated. The trust that plays an essential role in transmission can be stronger or weaker. The strongest type of trust, deference, is to believe that $\mathrm{p}$ because the speaker has said that $\mathrm{p}$, whatever your other reasons for or against believing that $\mathrm{p}$ - and so even if you have a lot of other evidence against it, even if $\mathrm{p}$ seems completely crazy to you. You take yourself to have sufficient reason to believe that $p$, whatever other evidence you have. A weaker kind of trust is more typical, you take that the speaker has said that $\mathrm{p}$ as some reason for believing $\mathrm{p}$, but a reason to be weighed against other reasons for believing (or disbelieving) that $\mathrm{p}$ - for instance how plausible a claim it is, whether you have any other evidence for or against $\mathrm{p}$. This may or may not give you sufficient reason to believe that $\mathrm{p}$. Knowledge that is partly based on testimony but also on other grounds is partly but not completely second hand: it is only partly transmitted.

Another complication lies in exactly what is transmitted. Taking someone's word, strictly speaking, is to accept the proposition that she explicitly asserted. But of course, often assertions require a bit of interpretation or convey more than is explicitly said, though implicature or 
implication. Knowledge of what was conveyed is partly testimonial and partly grounded in the hearer drawing the right conclusions - i.e. it is partly propagated - thus only partly second hand.

The literature on testimony tends to focus on the transmission of knowledge. There are good reasons for this. Transmission is a particularly efficient method of sharing knowledge. Provided that the speaker can put her knowledge into words that the hearer can understand, and that she (appropriately) trusts the speaker, the hearer gains knowledge. She doesn't have to do anything more. So there is scope for a massive division of epistemic labour: it may have taken many years of careful observation and powerful theorizing building on the work of many thinkers for an expert to come to know that p; and yet as soon as you are told that p, (in the right conditions) you know it too.

Let us now return to moral testimony, and see how the propagation/ transmission distinction applies.

A moral expert might give moral testimony intending the hearer to take her word and so get second hand moral knowledge. For instance, suppose you are thinking of giving away some money to charity but you are not sure which to support. So you ask me.

I say: "You should give to the Against Malaria Foundation." I intend that you come to know that you should give to the Against Malaria Foundation by taking my word. Your reason for belief will be my testimony, expressing my knowledge. Of course, you probably will weigh how plausible my claim seems, consider whether you have any other reasons to accept or reject the claim. Nevertheless if you do take my word, your knowledge will be completely (if you defer) or almost completely second hand.

On the other hand, I might intend my moral testimony to pass on moral knowledge by propagation. Propagation can look very similar to transmission: it too might be via an assertion like "You should give to the Against Malaria Foundation". But if I intend to propagate my knowledge rather than transmit it, I do not expect you to take my word. I do not intend to give you a reason for belief, but a practical reason, a reason for moral inquiry. You are supposed to discover what you can about this Foundation. Suppose you find that it is frequently recommended because it is very efficient at saving lives. This seems to you a very good reason for choosing a charity. So you conclude that you should give to the Against Malaria Foundation and you make your donation. Your moral knowledge is based on your own moral judgement and so is first, not second hand, and you are beginning to understand why you should give to them, so at least some moral understanding has been propagated too.

Propagation need not take the form of the bald statement of a moral conclusion. I might give you an explanation of why you should give to the Against Malaria Foundation, similar to the one sketched above. Suppose you find my argument compelling. If so, your moral judgement - that you 
should give to this charity - is based on moral reasons, expressed in this argument, not on my word. This is propagation not transmission. Of course the matter is complex: perhaps you took my premises on trust or took my word that the premises support the conclusion. Then the resulting conclusion is at least partly second hand, but it is nevertheless partly propagated too.

A moral assertion can be used for transmission or propagation, therefore, depending on the intentions of the speaker and on the mode of uptake of the hearer (that is, whether she takes what is said as a reason for belief or a practical reason to conduct an inquiry). But propagation can take other forms. Some speech acts are particularly suited to propagation as they can - and naturally are - taken as an invitation to inquire. So I might encourage you to think for yourself about the reasons for preferring one charity to another by asking you:

"Is it better to save more lives, or to save fewer lives? And so is it right for you to choose a charity where a donation will save more lives, or save fewer lives?"

Teaching by asking questions, the Socratic elenchus, is of course a familiar method in philosophy. But the strategy has played a very important role in ordinary moral practice too. The Wedgwood medallion, an extremely successful piece of persuasion on behalf of Abolitionism, made crucial use of a question:

Fig 1

Josiah Wedgwood's medallion, “Am I not a Man and a Brother?"

Of course, questions can be disguised assertions (as one might take "Am I not a man or a brother?" to be); in which case they might play the role of assertion in transmitting knowledge. But the Wedgwood Medallion is effective because the image and question together point you towards salient facts, but encourage you to acknowledge them for yourself. This is a man. His welfare and his dignity matter. So he ought not to be a slave held in chains. Having reached this conclusion, it is quite uncomfortable to be confronted by the image; you are moved to do something; and so you join the campaign.

Another important method of moral propagation is the use of analogy, by which I mean very broadly to include metaphors, parables, and so on. ${ }^{9}$ For instance:

"Suppose that you could push a button that saves five lives, or push a button that saves one life, what should you do?"

\footnotetext{
${ }^{9}$ For discussion of metaphor in partaicular, see Camp $(2006,2009)$.
} 
This analogy encourages you to think about the numbers of lives you could save. It does not directly tell you anything about charitable giving, and to draw a conclusion about that, you would need to consider whether you must save the greater number, and whether this really is the only or most important feature of giving to charity. Ideally, analogies prompt thinking about what is fundamentally morally important by representing a simplified situation or one that is easier to judge (e.g. one that removes self-interest) but that retains the underlying moral structure of the original case. $^{10}$

Again, moral analogy is very familiar both within moral philosophy and in moral practice generally. Here is a very famous Biblical example: David, the king of Israel, saw the beautiful Bathsheba bathing and had her brought to his palace, though she was already married to Uriah, one of the generals in his army. Bathsheba became pregnant and David sent Uriah to a particularly fierce battle where he was killed. God sent his prophet Nathan to tell David that he had acted wrongly. Nathan instead gave David an analogy:

There were two men in one city; the one rich, and the other poor. The rich man had exceeding many flocks and herds: But the poor man had nothing, save one little ewe lamb, which he had bought and nourished up: and it grew up together with him, and with his children; it did eat of his own meat, and drank of his own cup, and lay in his bosom, and was unto him as a daughter. And there came a traveller unto the rich man, and he spared to take of his own flock and of his own herd, to dress for the wayfaring man that was come unto him; but took the poor man's lamb, and dressed it for the man that was come to him. ${ }^{11}$

On hearing the story, David became very angry, condemned the rich man and in doing so - as he himself eventually conceded - condemned himself ("You are the man"). David also gained a better grasp of injustice. The rich man deliberately and cruelly took away the poor man's only lamb. Probably he gave it no more than a moment's thought; or if he did, regarded one lamb as worth so little attention that no one ought to make a fuss about it. David gets a glimpse of how the rich and powerful can be careless with other people's lives from the point of view of a victim. He begins to be able to take that same point of view elsewhere, and recognize similar casual wrongdoing, including understanding his own actions in that light.

Questions and analogies are at least as familiar if not more common in our moral practice than moral testimony proper. Whilst these can be used to transmit knowledge, (and conversely, as we have seen, assertions can be used to propagate knowledge), these more indirect methods are typically

\footnotetext{
${ }^{10}$ And in the less ideal cases, influenced by the hearer assuming that the speaker thinks there is a connection between the two, rather than her own judgement of the relationship

112 Samuel 12 (King James Version).
} 
used for propagation, and I take this to be evidence that moral propagation is at least as important as moral transmission both in our everyday moral practice and in moral philosophy.

I have described moral propagation as a method of passing on moral knowledge and moral understanding. But an objector might respond: "passing on" is the wrong word here. Propagation is not an epistemic process like transmission. It is merely causal. What the speaker says causes the hearer to think for herself and in doing so, she generates an entirely new piece of knowledge, or understanding. All sorts of things have a causal influence on us: things we see, or read, even a bump on the head - that can cause us to think about moral problems. But none of these are modes of teaching, and in none do we think of knowledge as passed on.

The objection is wrong: moral propagation is not mere causation. It does cause the hearer to think about morality, but it also shapes the way she thinks about it and direct and guide her thinking. At the very least, it prompts her to a particular investigation of a particular question or moral problem ("Am I not a man and a brother?). Setting the terms of an inquiry is an epistemic influence and not a negligible one. But moral propagation can do much more too. The speaker can give reasons for accepting the hypothesis, that will be independently assessed by the hearer, but nevertheless do not have to be thought up by her ab initio. She can make available conceptual resources for the hearer to understand the problem, frame the question so that various aspects are highlighted as important, and so on. She gives to the hearer the right sort of material and the right tools with which to work. So there is an important epistemic division of labour, but of a different kind than that involved in the transmission of knowledge. In propagation, the hearer does not have to think up the argument for herself, or come up with the analogy, though she has to grasp the analogy, find relevant points of similarity (or difference) and assess their significance and so on. So there is more epistemic work than transmission calls for, but less - sometimes much less - than if she were left entirely alone. In moral propagation, the speaker intentionally passes on moral knowledge (and moral understanding) to a hearer, by doing some epistemic work towards knowledge (or understanding) and directing and motivating the hearer to do the rest herself. It is quite plainly an epistemic process: a kind of moral teaching.

It may, however, still seem puzzling why anyone would opt for propagation when transmission is available. Transmission is efficient, direct and explicit; propagation is indirect, implicit, and requires extra work from the hearer. If she chooses not to investigate further, or does not conduct the investigation well, she will not end up with knowledge. So if the goal is to get the hearer to have moral knowledge, why would one ever choose propagation over transmission? The answer, as I shall explain in the remainder of the paper, is that propagation has some significant advantages over transmission. 


\section{Does moral propagation avoid the epistemic problems with moral testimony?}

Let us start with the epistemic problems of testimony. You want to learn whether $p$ is true, where $\mathrm{p}$ is some moral proposition (should I give money to charity? Which charity?) If you could identify an expert, understand what she says to you and trust her, you could gain knowledge, we will assume.

But who is a moral expert? Since you are not an expert yourself, you don't know. And you don't know how to find out either. In some domains, there are ways of identifying experts. Perhaps they have a track record that you don't need to be an expert to appreciate: good plumbers successfully fix your plumbing, and anyone can tell whether a tap is still leaking or not. Sometimes there are social markers of expertise: qualifications, certificates, and so forth. Sometimes the experts all agree with each other and so back up one another's claims to expertise.

None of this is true for morality. There are no uncontroversial markers of moral expertise, all the possible qualities of a moral expert are contested, and the most plausible candidates tend to disagree with each other. It follows that you have good reason to doubt anyone who claims to be a moral expert.

But transmission can succeed only if the hearer trusts the speaker, if she takes her word. So if you do, in fact, doubt anyone who claims to be a moral expert and as a consequence do not treat their testimony as a reason for belief, you cannot learn anything at all from them by transmission.

In an atmosphere of doubt, transmission fails. And it also fails whenever there ought to be an atmosphere of doubt, because if your reason for belief is the speaker's testimony, but you ought to doubt her, the doubt you should have undermines your reason for belief. So even in circumstances most favourable to the transmission of moral knowledge, where the speaker has moral knowledge, expresses it through testimony, is understood and is trusted, transmission may fail to pass on knowledge. You may get a true belief, but it will not be justified in the way required for knowledge, because you have reasons to doubt the speaker's expertise which defeat (undercut or undermine) your reason for belief. Why ought you to doubt a purported moral expert? You may have specific reasons to doubt a particular speaker. But there are also general reasons to be sceptical that anyone claiming to have moral knowledge is a genuine expert, because of the quantity of moral disagreement and sheer difficulty of many moral problems. So even if you do trust their moral testimony, arguably your trust is misplaced. 
I am not suggesting that the transmission of moral knowledge is impossible. It can succeed. You may have good reasons to think that the speaker has moral knowledge. Perhaps she has relevant experiences (that you do not), or has thought about it for longer, or has a good track record on similar issues. Then it may be reasonable to take her word and you will get moral knowledge by doing so. But if you do not take her word or if you do have reasons to doubt her expertise, then you cannot get moral knowledge by transmission.

What about propagation? Propagation is different, because it does not involve epistemic reasons - reasons to believe - at all, or at least not directly. Rather, it involves practical reasons of an epistemic kind: reasons to investigate, to conduct an inquiry into whether $\mathrm{p}$ is true. This sort of reason, to pursue an investigation, can have all sorts of different grounds. It could be that you think the hypothesis $\mathrm{p}$ is likely to be correct and you are looking for further confirmation. That sort of reason might be based on thinking that the speaker is reliable and trustworthy - very similar to the qualities you would look for in a moral expert whose word you should trust. But it can also be reasonable to investigate a hypothesis you expect to refute, or that you simply find interesting. An inquiry started for this sort of non-epistemic reason can still result in knowledge, provided that it is conducted properly. So reasons for inquiry are not the same as reasons for belief; they are much more various, and so the qualities of an expert propagator are correspondingly more varied. It follows that it may be easier to identify them than expert transmitters of knowledge: they ask questions that make you see things in a new light, or offer analogies you cannot help thinking about.

However, inquiries can lead nowhere and waste time or even mislead, as well as get you knowledge. Of course, in part that depends on how well the inquiry is conducted, and since it is you who is inquiring it is up to you whether it goes well or badly. But at the same time, propagation does not just give you reasons to start an inquiry, but also has a very significant epistemic influence on how that inquiry is conducted. The "framing" of the problem, highlighting certain features or encouraging you to conceptualize the problem in particular ways, can significantly influence a moral inquiry, for good or ill.

For instance, the question “Am I a man and a brother?" is a helpful framing for a moral inquiry into the slave trade. It draws attention to the humanity of the slaves and the hearer's relationship to them. And by showing the chains of slavery, the image prompts questions about how it is appropriate to treat a "brother". It is not surprising that this was a very effective slogan for the Abolitionist cause.

By contrast, the analogy that Nathan gave to David is less successful. Whilst David is persuaded that he has done wrong, and specifically that he has wronged Uriah, the analogy is significantly misleading. Nathan represents the key players as David and Uriah (the rich man and the poor man) and fails to represent Bathsheba (the lamb) as an agent at all. This is not a trivial omission 
that has no moral relevance. No one can understand fully why David's actions were wrong without knowing whether Bathsheba was his conspirator or his victim. If she was forced by him - that is, kidnapped and raped - as is possible and perhaps likely, she was very seriously wronged indeed. ${ }^{12} \mathrm{By}$ omitting any consideration of Bathsheba, the analogy fails to give David full moral understanding and arguably fails to give him moral knowledge, even though he ends up truly believing that he has done wrong. Moreover by reinforcing the idea that agency and interests of men are morally significant and those of women are not (or only insofar as they affect men), it is very likely to encourage false moral judgements in other situations too. Engaging with a poor analogy can have far-reaching damaging effects.

So by question, analogy or argument, a speaker can significantly affect not just whether you begin a moral inquiry but how you conduct that inquiry, and not just in the moment but in the further future too. So it is vital to find someone who will direct your inquiry along helpful rather than misleading lines, and it is not necessarily any easier to identify the right source for propagation than it is for transmission.

But nevertheless there is a significant difference. Propagation can be lucky in a way that transmission cannot. If you take the word of a speaker unreasonably (i.e. when you have no reason to think she is an expert and some reason to think she is not), even if you end up with the truth, you cannot get knowledge by transmission, for your reasons to doubt her undermine or undercut your reasons for belief, even if you yourself fail to appreciate this. But if you engage with propagation unreasonably, i.e. when you have no reason to think the speaker is an expert, and some reason to think she is not, your inquiry can nevertheless result in knowledge. Reasons for doubting the speaker do not undermine your reasons for belief via propagation, because those reasons come from your inquiry. You are not taking anyone's word. So propagation avoids some of the epistemic problems of transmission and can succeed in passing on moral knowledge in some circumstances where transmission by moral testimony fails.

4. Does moral propagation avoid the non-epistemic problems with moral testimony?

\footnotetext{
${ }^{12}$ Abasili (2011) outlines the debate between those who think that Bathsheba seduced David (e.g. Nicol 1997) and those who think she was raped (or that she did not instigate but did not object to the affair). Thanks to Katherine Southwood for the references.
} 
Epistemic problems do not exhaust the objections to moral testimony. There are also moral or practical problems. I will focus here on those relating to moral virtue. ${ }^{13}$ The problem is: even if a moral expert succeeds in passing on a piece of moral knowledge by transmission, it is not very plausible that she is thereby teaching virtue. One transmitted piece of propositional moral knowledge may allow you to make a good judgement now. But there is no guarantee that you can make good judgements in other, similar situations. Even learning a rule will not be sufficient, because the rule will need to be implemented in the right way, and most likely will have exceptions. Virtue requires not just that your moral judgements are right here and now, but that you are disposed to make right judgements in other similar situations too.

Virtue requires that you reliably do the right action, and the reliability has to be of the right kind: that your moral judgements (and ultimately, your moral actions) are responsive to the moral reasons, rather than other sorts of reason (even if they are correlated with moral reasons). A morally virtuous agent would correctly judge that she should keep a promise, precisely because she promised to do so. Not because it is good for her reputation. Nor because she was told it was the right thing to do.

What this suggests is that moral knowledge, especially "second hand" moral knowledge based on transmission, is not the cognitive component of moral virtue. Instead, what is required is moral understanding.

By moral understanding, I mean understanding why lying is wrong, or understanding why your action is right, and so on. ${ }^{14}$ Moral understanding involves a grasp of moral reasons, or more precisely, a grasp of the connections between moral reasons and moral conclusions. This grasp is best understood, I think, as a kind of ability or know how, to manipulate the reasons why the action is right. If you truly understand why your action is right, you are aware of the reasons why it is right, and if the situation were a bit different, you could correctly draw the conclusion that some other action would be right instead, and explain why. I call this kind of grasp cognitive control.

Cognitive control is kind of expertise over a domain that is different from having knowledge, even a lot of knowledge, since it involves the ability to go on to explain and to draw conclusions about new cases (an ability which is not guaranteed by any amount of propositional knowledge) . It is not difficult to see why this is so valuable in the moral domain. Having genuine moral understanding means having the ability to deal with competing moral reasons and reasons of other kinds, and to work out (correctly) what you ought to do. Moreover, it gives you the kind of sensitivity to reasons that allows you to draw your conclusions on the basis of the reasons that make them correct. So

\footnotetext{
${ }^{13}$ Howell (2014), (Hills 2009, 2010, 2015). Other objections involve the autonomy (Driver 2006) and authenticity (Mogensen 2017) of the resulting moral judgements.

${ }^{14}$ Hills $(2009,2010,2016)$.
} 
perhaps you judge that giving to this charity is right because by doing so you will save most lives; this is (I will assume) the right kind of reason for this judgement. Making the right judgements for the right reasons is a crucial component of moral virtue and of morally worthy actions (right motivation is also required). Both morally worthy action and moral virtue involve doing the right thing for the right reasons, ideally, with awareness of why what you are doing is right. Moral understanding enables you to be genuinely sensitive to morality in a way that is of vital practical moral importance. ${ }^{15}$

Like most abilities or know how, cognitive control comes from practice: that is, working out what matters morally in a situation, drawing moral conclusions on the basis of those features, and thinking about what would be the case if the situation were slightly different. It follows that transmission is a totally unsuitable means of passing on moral understanding. If you take someone's word that you should give to the Against Malaria Foundation, you have not worked out what is important in this situation (or in similar ones), and drawn your own conclusions. The whole purpose of transmission is to allow you to avoid all that epistemic labour. But if you want to develop cognitive control, you need to do the epistemic work yourself, in order to develop your own judgement. You cannot get or use moral understanding by transmission.

In addition, when you take someone else's word, your judgement is responsive to what they say, but not for the reasons that make it true. If a moral expert tells you that it is right to keep your promise, and you take her word, your judgment is not responsive to the reasons that make it right (that keeping a promise is right), but is instead responsive to reasons for taking her word (e.g. her good track record, her status as a religious leader etc). These are the wrong sorts of reason for a moral judgement. If you act on that basis, you may be doing the right action, but not for the right reasons.

So virtue cannot be taught by transmission, even if it can get you moral knowledge. Transmission cannot give you moral understanding, because it does not allow you to develop the dispositions that you need to make good judgements in other situations. And in taking the word of an expert, you are not responsive to moral reasons in making your moral judgement.

Moral propagation is different. Instead of taking someone's word, you yourself carry out a moral inquiry, and draw a conclusion yourself. Of course, as we have emphasized, moral propagation has an epistemic, not just a causal influence. It can draw attention to certain features and properties of an action, it can "frame" a moral problem in a particular way.

Take again the Wedgwood medallion: it prompts and directs your moral thinking about slavery. Suppose that, having seen the medallion, you oppose the slave trade on the grounds that you slavery is morally wrong, because it is contrary to the dignity and welfare of the people enslaved.

\footnotetext{
${ }^{15}$ Hills $(2009,2013,2015)$.
} 
Your judgement was made for the right reasons, and you understand - or begin to understand - why slavery is wrong. Propagation motivates moral inquiry and gives you the materials on which to work. The tools of moral propagation - analogies, questions, arguments - help the development of cognitive control, bringing us closer to the ideal of having our own moral understanding. Thus if we ask if moral understanding can be passed on by testimony, the answer is yes (by propagation) and no (by transmission).

One final point to note is that though a morally ideal agent will not make moral judgements on the word of others, she will on other matters, and especially any that can afford vital non-moral information. For instance, she will be very receptive to hear about the experiences which she has not shared, for instance. Testimony on this sort of matter will improve rather than hinder her moral understanding. She will be willing and eager to trust it. ${ }^{16}$

Earlier we asked why a moral expert might prefer an indirect and implicit method of passing on moral knowledge by propagation rather than the direct and explicit method of transmission. Now we can see that propagation avoids some of the epistemic problems that transmission suffers (in identifying whose word you should take on trust). But in addition, propagation supports the development and use of moral understanding and moral understanding is a crucial component in morally worthy action and in moral virtue. So there are very powerful reasons to favour moral propagation over transmission whenever propagation is available, that is, when the learner has the time and ability to develop her own moral understanding.

As we noted, moral judgements can be (and perhaps often are) partly based on transmission, and partly propagation. The arguments still apply: the more the judgement is based on transmission, the less it contributes to the development of moral understanding, and the less apt it is to play a role in morally worthy action and moral virtue.

5. Moral propagation, moral emotion and motivation

Moral virtue is partly a matter of moral understanding but the right motivations, feelings and emotions are also essential. So far I have said nothing about whether they can be taught. And we do not normally think of experts passing on feelings or motivations in the way that they pass on knowledge.

The transmission of moral knowledge through testimony certainly does not look promising as a route to moral motivation. The purpose of transmission is to pass on propositional knowledge.

\footnotetext{
${ }^{16}$ The importance of trusting testimony of this kind is emphasized by Fricker (2007) and the subsequent literature on epistemic injustice.
} 
Transmission works because the hearer takes the speaker's assertion to be a reason for belief. It is therefore wholly concerned with cognitive attitudes. Of course, some assertions will cause emotions and motivations in some people: if you are already care about justice, or about doing the right thing, you will be motivated to act by learning (by transmission) that some act is just, and motivated not to act by learning (by transmission) that some other act is morally wrong. But transmission here has merely latched on to an existing motivation (to do the right action); it has not extended or developed or refined that motivation, and it has not had any other effect on emotion or feeling. ${ }^{17}$ Someone could learn by transmission that other people's needs are as morally important as her own, without any motivation to do anything about it. ${ }^{18}$ Moral attitudes like anger, resentment, and guilt, tend to be caused by and made appropriate by, the aspects of the situation that make the action wrong, not by simply being told it was wrong, or being told what one ought to feel.

It cannot be said that moral transmission is a way of teaching the non-cognitive aspects of virtue. What about propagation? We have so far considered moral propagation as a method of passing on cognitive attitudes - knowledge and understanding - and we might think that, like transmission, that that is not just its main, but its only function. However, we have already seen that moral propagation passes on knowledge not by means of epistemic reasons (reason for belief) but practical reason (reasons for moral inquiry), and so successful moral propagation does have at least one notable effect on moral motivation, since it will result in a practically rational agent being motivated to start a new moral inquiry.

More importantly, that inquiry often, though not inevitably, will itself develop and refine noncognitive attitudes. A successful moral inquiry can be a dry, theoretical argument that does not draw on moral emotion. But often it will not be. Recall the examples of moral propagation, I gave earlier, the Wedgwood medallion and Nathan's parable of the rich and poor man. Both make essential use of moral emotions, at the same time as and in conjunction with developing moral understanding.

Take the Wedgwood medallion. The ambition of the Medallion is limited: there is no intention to convey an understanding of what it is like to be a slave, and therefore a full and detailed moral understanding of why slavery is wrong. Rather, its purpose is to convey at least some understanding that slavery is wrong and why it is wrong, and at the same time to motivate its audience to join the campaign against the slave trade.

The Medallion succeeds - when it does succeed - by drawing attention to, extending and developing already existing moral emotions. The image and text together are shocking. Many people will feel uncomfortable, at least, in being confronted with them. Not everyone will feel that way, of

\footnotetext{
${ }^{17}$ Fletcher (2016) makes a case against trusting moral testimony because it fails to produce the right sort of non-cognitive attitudes (see also Howell (2014)).

${ }^{18}$ Howell (2014), p. 404-5.
} 
course. Some people are thoroughgoing racists, some may be merely indifferent. But many will feel something, and as a consequence, will be more strongly motivated to think about the key question and its implications for the slave trade, and more likely to act on their conclusions, than they would otherwise have been. The question enlarges their moral sensibility, increasing their grasp of moral reasons and so develops their moral understanding. This new understanding in turn reinforces their discomfort and motivation to join the campaign. Cognitive and non-cognitive moral attitudes provide supporting feedback to each other; moral emotions and moral understanding entwine and develop in combination.

Consider now the parable of the rich and poor man. The story is told from the point of view of the poor man. David is encouraged imaginatively to identify with him, to understand the magnitude of his loss and to sympathize with him. On hearing the story, David was absolutely furious. He raged at the rich man; blamed him for his malicious or careless actions and tried to find a way to punish him and force him to make restoration. His anger was in itself an appropriate, i.e. virtuous, response. It also played a role in helping him recognize that the rich man acted wrongly and why ("he had no pity"), and motivated him to inquire further. Nathan successfully enlarged David's imaginative sympathy, and in doing so helped him to greater moral understanding. And in turn, this moral understanding allowed him to recognize that his anger was appropriate, that he was right to blame the rich man, and right to try to make restoration. When persuaded that the analogy applied to himself, the residue of that emotional response motivated him to repent and ask forgiveness.

On the other hand, as we have seen, the analogy was flawed. Whilst it encouraged David to take up the point of view of Uriah, it did not encourage - indeed may even have actively hindered his imaginatively sympathizing with Bathsheba, who is not represented as having agency or even personhood. David does not, then, have any particular feelings of anger or blame on her behalf, and as a consequence it never appears to occur him that his treatment of her may have been wrong. The analogy misleads him by drawing his attention, and his imaginative sympathy, away from one of the people his actions most significantly affects.

In short, when this analogy succeeds in passing on moral understanding and moral knowledge, it does so through the development of David's non-cognitive attitudes - anger, blame, and the desire to put right a wrong - by extending his imagination. These attitudes indicate to him that something is wrong, draw his attention to particular features of the situation, and motivate him to inquire further. And when the analogy fails to develop his moral understanding adequately, it is because it has failed to engage his emotions, through failing to engage his imagination in the right way.

So a final advantage of moral propagation over moral transmission is that it can and often does make use of our moral emotions and moral motivations. Anger, blame, admiration, resentment 
help us to recognize what matters morally and why it matters, and so play an important role in developing moral understanding. Moral understanding in turn shapes and refines our emotional responses, encouraging, shaping or undermining them, and directs our moral motivation towards appropriate action.

Of course, no method of teaching is guaranteed to succeed, and there are many ways that propagation can fail. Not everyone will be moved by an analogy: they will refuse to imaginatively identify with anyone else, or will do so ineptly, or will simply not care. And even if one is moved in the moment, there is no guarantee that the right cognitive and non-cognitive attitudes will persist. Virtue requires settled dispositions to think and feel the right way. One might reasonably doubt whether engaging with one question or analogy could change one's character.

Emotions do come and go, and a response prompted by moral propagation may need to be reinforced by further teaching, or by practice and experience, or both, to become a settled disposition to respond in the right way. However, there is no reason to think propagation cannot ever make deeper and longer lasting changes to character. The question "am I a man and a brother?" resonates in many contexts. You may find yourself returning to it in contemporary society, and feel anger, resentment or some kind of discomfort there too, and begin to a grasp of why certain kinds of discrimination, or segregation, or treatment by authority, are wrong. The question has given you the resources to respond in the right way, cognitively and non-cognitively, in new situations.

Not everyone can be taught virtue; not everyone can be moved in the right way emotionally either right now or in the future. But through moral propagation, it is possible to teach a willing and able learner the non-cognitive as well as the cognitive aspects of moral virtue.

\section{Conclusion}

Recent work on moral education has concentrated on the legitimacy of moral testimony. This is understandable, since testimony is the way we learn about most subjects. But learning from testimony, in the classic sense of transmission by testimony, is not the right way of teaching morality.

Once we distinguish propagation from transmission, we can do better. Moral propagation avoids many of the epistemic and non-epistemic problems of moral transmission. It also allows the possibility of developing and refining our moral emotions and motivations in combination with our moral understanding. It follows that moral experts who want to pass on moral knowledge and moral understanding should prefer moral propagation to moral transmission, even though it is less direct and efficient. We use moral propagation - explanation and argument, questions and moral analogies - all 
the time in moral philosophy and everyday moral practise. It is the most effective means of teaching virtue.

Nevertheless, it has its limits. It is not a replacement of other ways of forming a good character. Moral propagation succeeds, when it does, by supplementing the sorts of experience one would have in a good upbringing. It draws on our imagination, especially our capacities for imaginatively identifying with people whose lives may be different from our own, and our ability to imagine unfamiliar situations unfolding, and secondly, on our abilities to sympathize and form other emotional attitudes appropriately in response. Not everyone has or can develop these capacities. But guided in the right way, many of us can go beyond the narrow confines of our own lives, to enlarge our moral sensibility and develop our moral understanding, and thus come closer to perfect virtue.

I have emphasized the role of moral propagation in moral virtue, but the distinction between propagation and transmission is perfectly general, and in fact much teaching (not just moral teaching) is by propagation. Transmission is more common and effective in domains in which there are fewer problems in identifying experts, and where acquiring understanding is not as important as gaining knowledge (first or second hand). In those domains, the benefits of transmission - its directness and efficiency - tend to make it preferable to propagation. But of course there are many domains, from philosophy to science, where we want to understand as well as to know, or where we value first hand knowledge, and so there are many domains in which the propagation of knowledge and understanding can play an important role in addition to or instead of the transmission of knowledge. ${ }^{19}$

\section{Bibliography}

Abasili, A I, 2011. "Was it Rape? The David and Bathsheba Pericope Re-examined", Vetus Testamentum 61.1: 1-15.

Adler, Jonathan, "Epistemological Problems of Testimony", The Stanford Encyclopedia of Philosophy (Winter 2017 Edition), Edward N. Zalta (ed.), URL = <https://plato.stanford.edu/archives/win2017/entries/testimony-episprob/>.

\footnotetext{
${ }^{19}$ I would like to thank audiences at Princeton, at the Moral Sciences Club in Cambridge and a Normative epistemology workshop at Freiberg, to commentators Max Lewis and Liz Harman, to Roger Crisp, Dorothea Debus, Miranda Fricker and Stephen Wright who read earlier versions. I am grateful to the "Varieties of Understanding" Templeton project for support in writing the paper.
} 
Annas, Julia (2011). Intelligent Virtue. Oxford University Press.

Burge, Tyler (1993). "Content preservation.” Philosophical Review 102 (4):457-488.

Camp, E. 2006. "Metaphor in the Mind: The Cognition of Metaphor". Philosophy Compass 1 (2):154170.

Camp, E. 2009. "Two Varieties of Literary Imagination: Metaphor, Fiction, and Thought Experiments". Midwest Studies in Philosophy 33 (1):107-130.

Cholbi, M. 2007. "Moral Expertise and the Credentials Problem". Ethical Theory and Moral Practice 10 (4). Springer: 323-34.

Crisp, Roger (2014). “Moral Testimony Pessimism: A Defence." Aristotelian Society Supplementary Volume 88 (1):129-143.

Driver, Julia (2006). Autonomy and the Asymmetry Problem for Moral Expertise. Philosophical Studies 128 (3):619-644.

Enoch, David (2014). A Defense of Moral Deference. Journal of Philosophy 111 (5):229-258.

Faulkner, Paul, 2011.Knowledge on Trust. Oxford: OUP.

Fletcher, Guy (2016). Moral Testimony: Once More With Feeling. In Russ Shafer-Landau (ed.), Oxford Studies in Metaethics: volume 11. Oxford University Press. pp. 45-73.

Fricker, E. 2006. "Second-hand knowledge." Philosophy and Phenomenological Research 73 (3):592-618.

Fricker, M. 2007. Epistemic Injustice: Power and the Ethics of Knowing. Oxford: OUP.

Goldman, Alvin I., 2001 "Experts: Which Ones Should You Trust?" Philosophy and Phenomenological Research, 63 (1): 85-110.

Guyatt, M. 2000. "The Wedgwood Slave Medallion: Values in Eighteenth-century Design” Journal of Design History 13.2.

Hills, A. 2009. "Moral Testimony and Moral Epistemology”. Ethics 120.1 pp. 94-127.

Hills, A. 2010. The Beloved Self. Oxford: OUP.

Hills, A. 2013. "Moral Testimony" Philosophy Compass 8.6. pp. 552-559.

Hills, A. 2015. "The Intellectuals and the Virtues" Ethics 126.1 pp. 7-36.

Hills, A. 2016. “Understanding why” Nous 50.4. pp. 661-668.

Hopkins, R. 2007, "What is wrong with moral testimony?" Philosophy and Phenomenological Research, LXXIV: 611-634.

Howell, Robert J. (2014). "Google Morals, Virtue, and the Asymmetry of Deference." Noûs 48 (3):389-415.

Jones, K. 1999. “Second-hand moral knowledge” Journal of Philosophy 96.2 pp 55-78.

Lillehammer, H. 2014. "Moral Testimony, Moral Virtue, and the Value of Autonomy." Aristotelian Society Supplementary Volume 88 (1):111-127.

McGrath, S. 2007. "Moral disagreement and moral expertise". In Russ Shafer-Landau (ed.), Oxford Studies in Metaethics Vol. 4. Oxford University Press 87-108. 
McGrath, S. 2009. "The puzzle of pure moral deference." Philosophical Perspectives 23 (1):321-344. McGrath, Sarah. 2011. "Skepticism about Moral Expertise as a Puzzle for Moral Realism.” Journal of Philosophy 108 (3):111-137.

Mogensen, Andreas L. (2017). Moral Testimony Pessimism and the Uncertain Value of Authenticity. Philosophy and Phenomenological Research 95 (2):261-284.

Nickel, Philip, 2001. "Moral testimony and its authority." Ethical Theory and Moral Practice 4 (3):253-266.

Nicol, George G., 1997. "The Alleged Rape of Bathsheba: Some Observations on Ambiguity in Biblical Narrative", Journal for the Society of Old Testament 73, p. 43-54

Sliwa, Paulina (2012). "In defense of moral testimony." Philosophical Studies 158 (2):175-195.

Sliwa, P, 2017. "Moral Understanding as Knowing Right from Wrong.” Ethics 127 (3):521-552. 